https://doi.org/10.26754/ojs_aem/aem.2018293027

Recibido: 04/09/2018

Aragón en la Edad Media

Aceptado: 11/10/2018

29 (2018) 199-232

e-ISSN: $2387-1377$

ISSN: 0213-2486

\title{
CONFLICTOS Y ACUERDOS POR EL ACCESO A LOS RECURSOS AGROPECUARIOS EN LA FRONTERA NAVARRO-ARAGONESA DURANTE LA BAJA EDAD MEDIA
}

\author{
CONFLICTS AND AGREEMENTS FOR ACCESSING AGRICULTURAL RESOURCES \\ AT THE NAVARRESE-ARAGONESE BORDER IN THE LATE MIDDLE AGE
}

\author{
Mikel URSUA LIZARBE \\ Investigador independiente \\ Universidad del País Vasco (UPV/EHU)
}

Resumen: El presente trabajo tiene como objetivo estudiar la violencia entre las comunidades fronterizas así como las resoluciones tomadas para retornar a la paz durante la Baja Edad Media en la frontera navarro-aragonesa. En un periodo de expansión extensiva del sector agropecuario, las comunidades ejercieron presión sobre los espacios fronterizos, chocando en muchas ocasiones con los intereses de sus vecinos. Los grandes perjudicados de estas tensiones, administración real y villas, ante la poca funcionalidad de los mecanismos ordinarios, tuvieron que recurrir a métodos extraordinarios como tratados, amojonamientos o facerías.

Palabras clave: Navarra, Aragón, Baja Edad Media, recursos agropecuarios, violencia, resolución, facería.
Abstract: The main goal of this paper is to study the violence among border communities as well as the resolutions considered to return to peace in the Late Middle Age at the Navarrese-Aragonese border. In a period of extensive expansion of the agricultural sector, the communities caused pressures on border areas, usually clashing with the interests of their neighbors. The main injuries of these pressures, royal administration and towns, due to the lack of functionality of ordinary mechanisms, had to appeal to extraordinary mechanisms like treaties, demarcations or faceries.

Key words: Navarre, Aragon, Late Middle Age, agricultural resource, violence, resolution, facerie. 


\section{Introducción}

La frontera medieval ha ejercido un alto grado de atracción sobre la historiografía no sólo hispana sino también anglosajona, atraída por los ingredientes que reunía la península: la frontera entre dos religiones y culturas, antagónicas y en constante conflicto, aunque esta última etiqueta ha caído en desuso. Los investigadores han subrayado la permeabilidad de dicha frontera, subrayando la enorme interacción económica y cultural que existió entre ambos espacios (Glick, 1994).

Sin embargo, en este trabajo, vamos a centrarnos en una de las fronteras cristianas medievales, la localizada entre los reinos de Navarra y de Aragón. Un espacio bastante olvidado por la historiografía navarra y aragonesa en comparación con otros espacios fronterizos como la frontera de los malhechores, situada entre las actuales comunidades autónomas de Navarra, Guipúzcoa y Álava. En estos estudios, el polifacético Arturo Campión (1911: 67-75; 1915: 241-423; 1983: 203-286) reconoció en la segunda mitad del siglo XX la gran importancia de una fuente clave para conocer los problemas fronterizos: los registros de Comptos. Debió de pasar algo más de medio siglo para que en la década de los ochenta volviesen a surgir estudios sobre esta temática de mano del Departamento de Historia, Geografía y Arte del País Vasco de la Facultad de Filosofía y Letras de la Universidad de Deusto (Achón, 1988: 257-266; Orella y Achón: 1988, 267-276 ; Saíz y Achón: 1988, 277-286; Herrero y Orella, 1988: 491-500; Orella, 1984: 25-100; 1985: 463-492). Más recientes son los estudios realizados por Zabalo (2004: 477-510; 2005: 53-110) o Fernández de Larrea y Díaz de Durana (2005: 171-205).

Todas estas investigaciones permitieron entrever que la existencia de un límite entre dos jurisdicciones siempre creó disputas y enfrentamientos entre los habitantes de ambas divisorias, y que esta problemática no sólo quedaba circunscrita a la frontera noroccidental navarra. De este modo, algunos medievalistas se sintieron atraídos por la frontera sudoccidental entre Navarra y Castilla (Azcárate, 1986: 333-344; 1988: 329-336) o la frontera del norte entre Ultrapuertos y la corona inglesa (Aparicio, 2007: 9-31; 2011: 9-26).

La historiografía aragonesa ha sido menos fecunda en lo que a investigaciones sobre frontera cristianas se refiere. Aparte de la celebración en 1992 de un seminario sobre las sociedades de frontera en el departamento de Historia Medieval de la Universidad de Zaragoza (publicado en 1993), destacan los 
trabajos de Bonifacio Palacios sobre la frontera castellano-aragonesa en época de Jaime I (1979: 475-495) y de Diago Hernando sobre las consecuencias de las guerras entre los Trastámara en las comarcas de frontera en el siglo XV (2013: 304-313).

La frontera navarro-aragonesa ha sido estudiada tanto por historiadores aragoneses como por navarros, a través de investigaciones sobre determinados periodos cronológicos o espacios concretos. Utilizando únicamente documentación aragonesa, encontramos el trabajo de Sáinz de la Maza que examina las hostilidades fronterizas durante el reinado de Jaime II de Aragón (1997: 409-423); o el de Abella Samitier sobre la comarca de la Valdonsella, que analiza, sobre todo, el siglo XV (2011: 335-347). Otro trabajo muy interesante, en este caso centrado en el conflicto intercomunitario más importante de esta zona entre Sangüesa y el Real, fue realizado por David Maruri, investigador y fundador de la revista de estudios históricos de Sangüesa, Zangotzarra, y por la historiadora del derecho Consuelo Juanto Jiménez (Juanto y Maruri, 1999: 11-107). El aspecto más atractivo de esta publicación es la interacción y uso de diversos fondos documentales navarros y aragoneses, siendo especialmente útil el Archivo de Protocolos de Sos que conserva una gran cantidad de documentos del siglo XV. Por último, hay que nombrar el trabajo sobre la Hermandad navarro-aragonesa de frontera de 1469 (Castellano, 1995: 121162) donde el autor transcribió y recogió las ordenanzas que regularon dicha colaboración.

\section{Fuentes}

Para esta investigación hemos recurrido a la utilización casi exclusiva de documentación procedente del Archivo Real y General de Navarra, más concretamente de la sección de Comptos, la más importante y prestigiosa para conocer la historia navarra (Segura, 2013: 119). Las subsecciones de las que hemos extraído la documentación son esencialmente tres:

En primer lugar, la subsección denominada Registros de Comptos. Creados a principios del siglo XIII, de carácter anual, cumplía una función económica al gestionar y controlar las finanzas públicas. En ella, los oficiales reales anotaban cuidadosamente todos los ingresos y gastos derivados del ejercicio de poder. Los merinos, agentes más importantes de las merindades, ejercían el poder ejecutivo y judicial, ofreciéndonos información sobre los 
problemas que sucedían en la frontera. Sin embargo, debemos señalar que la limitación más reseñable es la brevedad de la información, pues su objetivo no es detallar sus acciones militares, los debates de las reuniones o el desarrollo de un juicio...; en última instancia lo que trata es de justificar el ingreso o el gasto derivado del ejercicio de sus tareas como oficial de la administración. En este trabajo hemos utilizado los registros más antiguos desde 1259 hasta 1330; la gran mayoría han sido publicados en los doce tomos de la colección Acta Vectigalia Regni Navarrae, financiada por el Gobierno de Navarra.

En segundo lugar, la subsección titulada Libros de Fuego. En ella se incluyen «relaciones fiscales o listas cobratorias elaboradas por la administración navarra para el cobro de las denominadas "ayudas" o "cuarteles"» (Monteano, 1996: 309-310). Al igual que los registros de Comptos, esta documentación tenía una finalidad fiscal, repartir entre la población las ayudas económicas que con el paso de los años pasaron a convertirse en impuesto ordinario. Para la Baja Edad Media conservamos dos libros de fuegos: el primero de ellos de 1366 tras la concesión por parte de los Tres Estados a Carlos II de una ayuda económica de 40.000 florines; el segundo realizado entre 1427 y 1428 en donde se hizo un nuevo estudio para repartir las cargas fiscales de manera más equitativa. Se trató, en resumidas cuentas, de una actualización de las listas ya que las mortandades y otras causas habían provocado una caída demográfica en muchos núcleos navarros, corriendo el peligro de quedarse despobladas muchas de ellas por la enorme carga económica que debían soportar (Monteano, 1996: 312).

En tercer lugar, la subsección Documentos. Gran parte de la documentación de los siglos XIII y XIV de este inmenso fondo junto al de otras secciones como Códices y Cartularios o Clero han sido publicados por la institución Eusko Ikaskuntza dentro de su colección Fuentes documentales medievales del País Vasco.

Sin embargo, no solo hemos utilizado documentación del AGN, sino también otros procedentes de archivos locales como el del valle de Roncal. Del mismo modo, la existencia de dos grandes jurisdicciones en esta frontera oriental nos ofrece a su vez la existencia de documentación conservada en territorio aragonés. Me estoy refiriendo concretamente a la documentación utilizada en este trabajo, procedente del Archivo de la Corona de Aragón, del Archivo Municipal de Ansó y del Archivo de Sos del Rey Católico (Abella, 2009). 


\section{La lucha por el acceso a los recursos}

Una de las primeras menciones encontradas sobre problemas de límites data de finales del siglo XIII. En ella se expone cómo existía en 1278 una contienda entre los vecinos de Sos y Filera por una parte, y los de Sangüesa por otra, enfrentados por motivo de los mojones de las fronteras (Zurita, 1985: 24; Moret y Alesón, 1969: 429). Que esta sea la primera mención no significa que sea el primer enfrentamiento entre localidades de Navarra y Aragón. Seguramente los primeros conflictos comenzaron tras la muerte de Alfonso I el Batallador con la división del territorio en dos reinos diferentes: Pamplona y Aragón. Una frontera que experimentó variaciones a lo largo de las décadas del siglo XII para quedar, más o menos fija, a partir del primer tercio del siglo XIII. La fosilización de la frontera no significó el fin de los problemas por delimitarla o por el aprovechamiento de ciertas zonas localizadas espacialmente sobre la raya, como veremos a lo largo de este apartado. Hubo villas que trataron de ejercer su dominio sobre el entorno, no sólo el de su territorio, sino también del espacio de frontera. El motivo de la disputa varió en función de cada caso. Los enfrentados no discutieron por el límite propio, en el fondo lo que preocupaba a los habitadores de ambos lados de la raya fue conservar o incluso incrementar las zonas dedicadas al aprovechamiento agrícola, ganadero o forestal. En ocasiones resulta confuso poder discernir el aprovechamiento que se daba a cada espacio, por lo que hemos decidido trabajar esta cuestión en un mismo apartado.

La lógica y la información de los documentos nos llevarían a pensar que en aquellos territorios situados al norte de una línea imaginaria trazada por las sierras de Illón y de Leyre, en donde la ganadería era la actividad predominante, las disputas guardarían relación con el aprovechamiento ganadero. El libro de fuegos de 1427 permite conocer la economía de cada lugar y para el caso de las localidades roncalesas señala claramente que la mayor parte de la población vive de la actividad ganadera; la encuesta realizada a los habitantes de la localidad de Roncal señala que biuen sobre los ganados que mantienen, puesto que la agricultura debido al terreno y a la climatología no es suficiente para abastecerse: no cugen pan sino para dos meses et bino no tienen que no an binnas. ${ }^{1}$ En cambio, la localidad de Burgui situada a escasos kilómetros de Roncal, muestra una economía un poco diferente, pues producía pan para

1 Archivo General de Navarra, Comptos, fuegos, 7,155 r. 
ocho meses y vino para uno. De todas formas, la actividad agrícola no fue la predominante en la zona norte navarra donde la ganadería constituyó la base económica de sus habitantes. ${ }^{2}$ Posiblemente estos datos puedan pecar de ser más cualitativos que cuantitativos y en ellos se tratase de exagerar el nivel paupérrimo de vida de la propia población ya que, en última instancia, lo que estaba dilucidándose era la adecuación del cuartel que debían pagar. Seguramente, no toda población vivía de la ganadería, pero si podemos saber que la mayor riqueza se encontraba en ella. Los poseedores de gran cantidad de reses, aunque desconozcamos si eran quienes accedían a los cargos de gobierno de valle, posiblemente lograron influir en las directrices ganaderas y dedicar a pastos las mejores tierras, reducidas en número por el condicionante ecológico que limitaba la práctica de la agricultura.

Esto unido a un momento de enorme presión demográfica sobre el espacio, explicaría el intento de colonizar nuevas tierras de cultivo por parte de habitantes del valle de Roncal, más concretamente de Burgui, quienes en 1305 pusieron en cultivo el término de Sas situado en el límite fronterizo, el cual era asumido como propio tanto por la iglesia de Salvatierra de Esca como por la población de Burgui. Comenzó un enfrentamiento por el cobro del diezmo pues la pertenencia a uno u otro término haría variar el beneficiario. Tras poco más de un año, se dictó sentencia favorable a los de Burgui, pero los habitantes de Salvatierra en total desacuerdo con la resolución decidieron llevar al término de Sas su ganado e hirieron a varios hombres de Burgui. La respuesta navarra no se hizo esperar, capturando a ocho hombres de la localidad aragonesa (Sainz de la Maza, 1997: 420-421).

Pero para los gobernantes del valle era la ganadería y por tanto el aprovechamiento del espacio para su beneficio, lo que mayor preocupación les creaba. Con este objetivo se celebraban vistas anualmente en donde se negociaban los límites de las zonas de aprovechamiento con los valles colindantes entre otros asuntos, como señala el libro de fuego de 1427 en la encuesta realizada a la comunidad de Roncal, la cual gastaba grandes sumas de dinero en las «vistas con los de Saluatierra de Aragon, con los de la baill d'Ansso, de la baill d'Echo, de la baill d'Aspa, de la baill de los baretones, de la tierra de Sola, de la baill de Sarasaz». ${ }^{3}$ Esto era algo cotidiano para Roncal, pero en ocasiones las disputas llegaban a ser tan enconadas que las simples vistas no bastaban y

2 AGN, Comptos, fuegos, 7, 153v.

3 AGN, Comptos,fuegos, 7, 155r. 
comenzaban costosas negociaciones para la comunidad. En la de 1427, el valle tuvo que afrontar el gasto de mil florines por el mantenimiento de los comisarios «mossen Godoffre et mossen Rodrigo et otros muchos que se reunieron con los del valle de Ansó por cierto pleito et debate que ouieron». ${ }^{4}$ Parece ser que la comunidad del Roncal tuvo a lo largo del periodo bajomedieval una relación en ocasiones muy conflictiva con la vecina Ansó. Por ello se llegaron a acuerdos escritos, denominados facerías como la de 1369 entre Ansó y la villa de Isaba o la de 1407 entre la comunidad del Roncal y la de Ansó (Tomás y Laliena, 2016: 184-185). Todo ello pone de relieve la existencia de los problemas y roces surgidos por la convivencia y explotación común de una zona fronteriza.

Pero la negociación por el aprovechamiento pastoril no sólo se estableció en los acuerdos entre valles pirenaicos. Conservamos facerías entre comunidades de ambos reinos localizadas más al sur, en las que se reguló claramente, además de la actuación conjunta contra una serie de delitos, aspectos relacionados con la ganadería. Uno de estos casos es el protagonizado por Lumbier, localidad que en 1427 decía vivir sobre la labrança de pan et vino, sin ninguna mención a la ganadería como medio de subsistencia; ${ }^{5}$ el otro es el de Peña, localidad que también vivía sobre la labrança de pan et vino aunque, en este caso, se señala las posesiones de algunos pocos ganados, insuficientes para ocupar todos los pastos puesto que el municipio obtenía dinero por la venta anual de herbagos et pazto. ${ }^{6}$ Es evidente que el aprovechamiento ganadero y, por tanto, las disputas por el mismo no fueron exclusivas de la zona norteña.

El gran enfrentamiento del sector central tuvo lugar en el entorno de la desembocadura del río Onsella en el Aragón, y estuvo protagonizado desde principios del siglo XIV por Sangüesa y El Real, ${ }^{7}$ sumándose otros actores posteriormente. Esta zona de frontera ya había sido espacio de discordia entre Sos y Sangüesa en 1278, pero la creación de una nueva villa de carácter estratégico para los aragoneses, supuso el comienzo de una larga pugna por controlar este espacio. En el año 1300, Jaime II fundó La Real para reagrupar en un mismo núcleo los lugares despoblados y destruidos de Ul y Filera (Romano, 1977: 435). El rey trató de poblarla otorgando una serie de privilegios (Juanto

AGN, Comptos, fuegos, 7, 155r.

AGN, Comptos, fuegos, 7, 208v-209r.

AGN, Comptos, fuegos, 7, 18v.

Otros autores utilizan el género femenino, La Real. En este caso, utilizaré el género masculino siguiendo las indicaciones de: Gran enciclopedia navarra (1990), Pamplona, Caja de Ahorros de Navarra. 
y Maruri, 1999: 29-30). El primer conflicto tuvo su origen en la donación realizada por el monasterio de Leyre al rey aragonés de tres villas: Lerda, Undués y Añués, a cambio de la iglesia parroquial del Real (Fortún, 1993: 680). El alcaide sangüesino, que hasta entonces tenía bajo su tenencia las localidades de Añués y Lerda, se sintió damnificado y decidió hostigar las localidades de Undués y Lerda al exigirles la pecha. El monarca aragonés consciente del enfado del alcaide, pidió al monasterio legerense que le compensase con otra tenencia. Dicho resarcimiento nunca llegó a realizarse, por lo que el alcaide junto a la población de Sangüesa pasó a reclamar el uso y posesión de El Real (Juanto y Maruri, 1999: 45). El conflicto tomó un cariz muy violento en las tres primeras décadas del siglo XIV con la erección de torres y fortalezas en El Real en 1315 por parte de los zangozarrak, con el asedio de la localidad aragonesa en 1317, la invasión armada en $1325 \ldots$ Las idas y venidas tanto de unos y de otros son numerosísimas en el periodo bajomedieval, creando una enorme preocupación entre las autoridades de ambos reinos. Se trató de un conflicto en el que se sucedieron los momentos hostiles y la concordia, aunque esta última no fue definitiva hasta la conquista navarra de Fernando el Católico.

En 1368 el lugar de El Real, conquistado previamente por Carlos II de Navarra, fue donado a Sangüesa. El propio monarca aragonés, Pedro IV, reconoció el dominio zangozarra, provocando los recelos de Sos (Juanto y Maruri, 1999: 48). A partir de entonces, esta localidad pasó a protagonizar en detrimento de El Real, la lucha con Sangüesa por dominar el espacio fronterizo. Deseosa de controlar todo su entorno, tuvo largos enfrentamientos con todas las localidades vecinas, incluso con las pertenecientes a la misma corona aragonesa. En 1430 Sos compró al monarca aragonés la villa del Real y comenzó a reclamar todas sus posesiones, aldeas y términos pertenecientes al mismo (Juanto y Maruri, 1999: 48). Parece ser que el antiguo término del Real no fue incorporado íntegramente por los navarros en el siglo XIV pues como señala la documentación de Sos, Juan de Urriés fue el elegido después de 1386 por las autoridades de la localidad para que tomase posesión de todas las aldeas pertenecientes al Real: Undués de Lerda, Añués y Filera (Juanto y Maruri, 1999: 48-49).

El enfrentamiento se complicó aún más en la segunda mitad del siglo XV con la aparición en escena de dos magnates laicos: el señor de Xabier y la casa de los Alvarado. Esta última adquirió en septiembre de 1464 la villa de El Real «en virtud del privilegio otorgado por Juan II de Navarra y Aragón en 
remuneración de los servicios prestados al monarca en las guerras» (Juanto y Maruri, 1999: 51). El señor de Xabier por su parte argumentaba «haber gozado del derecho de pastos en El Real, puesto que tenía casa en Sangüesa y derecho de vecindad en ella» (Juanto y Maruri, 1999: 52). También señalaba que tenía la vecindad de Casales de Lerda, la cual incluía derechos de pasto sobre El Real y además poseía una casa en la vecina Undués de Lerda. Podemos resumir las décadas finales de la Edad Media en este sector como el escenario de lucha entre cuatro actores por dominar el territorio del Real. Las autoridades de ambos reinos sufrieron grandes dificultades para contentar a los cuatro interesados.

La intervención de Sos en la disputa por El Real no fue más que un episodio del intento de la villa aragonesa por expandir su influencia y control no solo en el espacio aragonés sino más allá de la frontera navarra. Efectivamente esta villa trató de dominar todo su entorno, no solo el aragonés sino incluso también el navarro. Los vecinos núcleos también se vieron afectados por esta pugna como la villa de Peña, que en 1412 recibió la merced real de no pagar «el tercero quarter» por los enormes gastos que tenía el lugar «en la reparaçion de lur fortaleza como en los afruentos que han todos días con los de Sos». ${ }^{8}$ En 1427 los habitantes de Cáseda, seguramente relacionado con esta problemática, se quejaban de que «an muchos afruentos et estorbos con los frontaleros por quanto son situados en frontera». ${ }^{9}$

Munita, en su tesis doctoral sobre el monasterio de la Oliva (Carcastillo), muestra cómo en estas disputas de frontera no sólo actuaron los concejos. También ejercieron como protagonistas señores eclesiásticos como el abad de la Oliva que sufrió los ataques de Sos y de Castiliscar. Desde finales del siglo XII y durante la primera mitad del XIII, los habitantes de ambas localidades se enfrentaron al monasterio de la Oliva por motivo del establecimiento de sus límites territoriales en el entorno de la granja de Figarol, posesión del monasterio. Esto respondía, en palabras de Munita (1995: 385), «a una doble problemática, por una parte, delimitar entre unos y otros las zonas dedicadas al cultivo y al pastoreo, y por otra, frenar la ocupación por los cistercienses de tierras diezmeras con el consiguiente detrimento de las iglesias parroquiales». El monasterio, al hacerse con mayores espacios, podía dificultar el tránsito de sus ganados al arroyo de Valtriguera, motivo por

8 AGN, Comptos, documentos, caj.100, N.63, 3 (1), 1r.

9 AGN, Comptos, fuegos, $7,17 \mathrm{v}$. 
Mikel Ursua Lizarbe

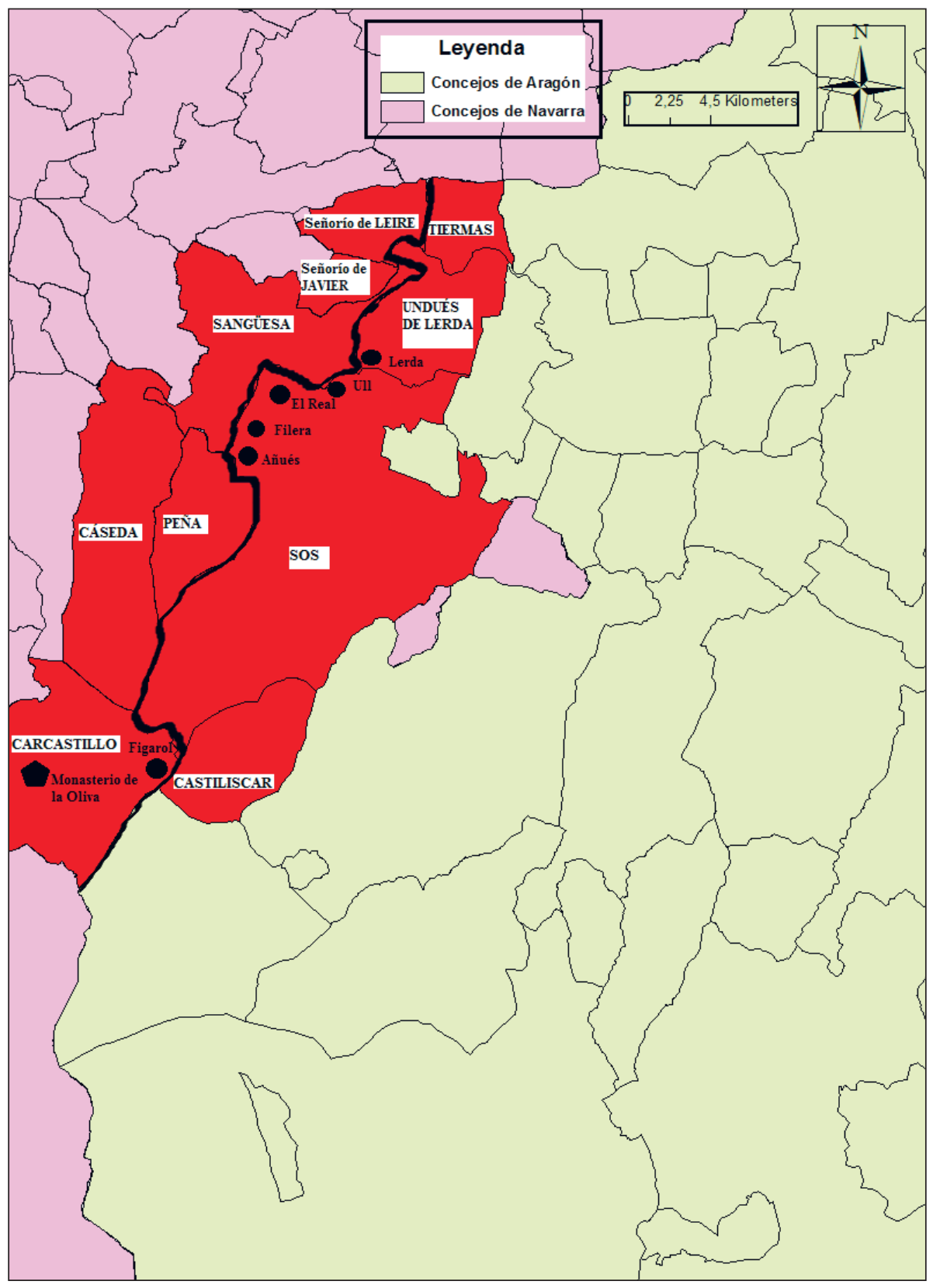

Mapa 1. Localidades y señoríos enfrentados en la zona central de la frontera navarro-aragonesa. 
el cual los aragoneses se encontraban descontentos. Los enfrentamientos fueron continuos, sufriendo la Oliva robos y el paso del ganado por sus propiedades. A pesar de haber alcanzado un acuerdo en 1280, en el siglo XIV volvió a resurgir el conflicto: en el año 1316 varios hombres de Castiliscar protagonizaron el prendamiento de los bueyes de Figarol, la invasión de los campos de avena con sus reses y la tala de las mieses que tenía la granja. Tras volver a solucionarse el problema a través de un acuerdo entre los implicados, las hostilidades resurgieron dos siglos más tarde: en 1508 los de Sos rompieron los mojones para crear confusión y tratar de reavivar el conflicto por el límite (Munita, 1995: 386-388).

Pero la Oliva no fue el único señorío monástico localizado junto a la raya. En la Sierra de Leire, el monasterio del mismo nombre, también expandió sus intereses por el aprovechamiento ganadero y forestal de la zona más allá de las fronteras navarras. En este caso su conflicto más sonoro fue con la vecina Tiermas. Entre 1332 y 1334 el señorío legerense recurrió a las más altas instancias jurisdiccionales con tal de recibir el reconocimiento de sus derechos a gozar de pastos y bosques en Tiermas, obteniendo finalmente una respuesta favorable. Pero entre 1368 y 1371 el concejo aragonés, descontento con el uso que hacía el cenobio de sus términos, trató de impedir el disfrute de los mismos, llegando finalmente a un acuerdo que limitó los derechos del dominio legerense en 1447 (Fortún, 1993: 686, 712).

En el sur de la franja oriental navarra fue la agricultura la actividad hegemónica y por tanto fuente de las disputas. El crecimiento agrario de este periodo era extensivo, es decir, se realizaba a través de la puesta en cultivo de nuevas tierras por lo que los habitantes buscaban cualquier terreno, incluso fuera de su término, para la labranza. Esta expansión en zona de frontera contaba con el peligro de enfrentarse a la comunidad vecina. Pero no fue la actividad agrícola lo único que demandó tierras, también eran necesarias para los pastos, que a su vez empujaba a las zonas de bosque y arboladas, medio para acceder a la materia prima imprescindible en este periodo pues servía para la construcción, como combustible, artesanía...

La información procedente de loa registros de Comptos resulta muy ambigua al no indicar en la gran mayoría de las ocasiones el motivo de la disputa y citar, simplemente, a los enfrentados. Entre la segunda mitad del siglo XIII y primer tercio del XIV en la merindad de Tudela hubo varios enfrentamientos entre localidades. En 1266 parece ser que hubo una enorme actividad en la frontera con Aragón que afectó a las villas de Cortes y Buñuel (García, 1989: 
264) sin especificar el motivo ni la disputa. En la década de los ochenta del siglo XIII tuvo lugar la guerra de las Vísperas Sicilianas, que afectó directamente a Navarra. El rey francés que tenía a su hijo Felipe I el Hermoso como rey consorte en Navarra, en su enfrentamiento con Aragón decidió utilizar el reino de su hijo como cabeza de puente. La política exterior navarra pasó a depender totalmente de la francesa, más aún cuando el rey consorte navarro heredó el trono francés en 1285. Esta disputa militar produjo una enorme inestabilidad en la frontera entre ambos reinos, siendo aprovechada la situación por las localidades fronterizas para poder hacer grandes males a sus antiguos enemigos. En 1284 «Furtunii Symonis et Lupi Ortici, et equitum et peditum» tuvieron que ir en auxilio de Cascante pues existía el rumor de que García Simon «cum gentibus Tirassone» quería destruir la villa de noche. Al año siguiente, hubo una congregación en Tarazona para atacar Monteagudo y otra en Tauste. En ese mismo año, la comunidad de Tudela «cum domno Johanne Nunni» fueron a destruir «aquam Tirassone». La tensión impedía el funcionamiento normal de la vida en dichas poblaciones por lo que en ocasiones trataron de negociar treguas entre las localidades en pleno contexto bélico. Tudela fue quien encabezó en 1286 dichas treguas con las vecinas Tarazona, Tauste, Borja y El Bayo (Carrasco \& Tamburri, 1999: 6-8).

Como podemos observar estas disputas solían estar focalizadas en las grandes localidades del entorno. No resulta extraño observar a la ciudad de Tarazona protagonizando incursiones contra sus vecinas Monteagudo y Cascante como entre 1350 y 1352 cuando atacaron a esta última, robando ganados e incluso llegando a violar la iglesia parroquial al hurtar muchos ornamentos (Fernández, 1978: 108). En 1315 las autoridades de Tarazona invadieron Tulebras mientras perseguían a varios malhechores de su reino. Pero esta no fue la única actuación del merino en dicho año: también negoció las treguas de Tarazona con Cascante (Carrasco, Beroiz \& Mugueta, 2005: 129). Detrás de estas confrontaciones solía estar el interés por acceder a recursos vitales como el agua. Este fue el motivo del enfrentamiento de 1312 entre Mallén (Aragón) y la vecina Cortes (Carrasco y Mugueta, 2004: 117).

La documentación nos deja entrever la existencia de un espacio muy codiciado y disputado, las Bardenas, por sus pastos, por la posibilidad de poner en cultivo enormes extensiones y por sus bosques. El acceso al mismo produjo roces no solo entre comunidades fronterizas, sino también entre las congonzantes del mismo reino (Díaz de Durana y Fernández de Larrea, 2002: 52-53). Una de las localidades más interesada en controlar dicho espacio fue la villa 
de Tudela. La presión demográfica sobre el territorio conduciría al municipio a tratar de dominar grandes espacios localizados en su entorno como las Bardenas. En 1294 la capital ribereña tuvo que mandar 30 hombres para que vigilasen la madera de los árboles por razón que los del Bayo querían llevársela (Carrasco y Tamburri, 2001: 28). Tres años después aún continuaban las disputas entre ambas localidades, junto a Cabanillas y Fustiñana por el uso del monte, motivo por el cual se reunieron en el castro de la Foç para acabar con la discordia (Carrasco, Tamburri y Mugueta, 2001: 41). Pero Tudela no fue la única interesada en la zona, la otra gran población situada al sureste del codiciado espacio, Tauste, también trató de aprovecharse de los recursos ofrecidos por la Bardena. En 1328 el merino de Tudela tuvo que acudir en tres ocasiones contra el concejo de Tauste porque «uvieron taiar et estruir la Bardena del rey». En una de ellas, las autoridades navarras apresaron a varios hombres, les quitaron cinco asnos y una mula y además les obligaron a pagar multa (Carrasco y Beroiz, 2009: 198). La actividad por parte del merino no terminó ahí, decidiendo mantener una comitiva de 10 hombres que custodiasen «nemus siue bardenam» (Carrasco, Goñi y Mugueta, 2010: 223). Posiblemente el disfrute de la Bardena fuese también el origen del conflicto mantenido en 1330 por los concejos de Tauste y Buñuel en el cual los primeros habían segado unas piezas a los navarros, lo cual produjo una enorme confrontación que tuvo que ser sosegada por la intervención del merino. ${ }^{10}$ En años posteriores hubo periodos en donde las disputas se recrudecieron, como en 1337 (Barragán, 1997: doc. 117) o 1388, momento en el que las localidades afectadas fueron convocadas por la comisión navarro-aragonesa para oír sus quejas y dictar una resolución (Esteban, 1921: 178).

Concluiremos este punto con un último episodio susceptible de ser incluido en este elenco. El protagonizado por señores laicos que se enfrentaron contra concejos. La familia Rada - y más concretamente el señor Egidio o Gil de Rada - fue quien lideró los ataques contra la vecina Monteagudo en dos años diferentes: 1312 y 1328. Desde la villa fronteriza que pertenecía a su señorío, Novallas (Zaragoza), realizó las embestidas. En la primera de ellas, «interfecit octo homines dicte uille et inuadebat eos» (Carrasco y Mugueta, 2004: 116). En la segunda, «mató 4 honbres et una mujer de los de Montagut et los tenia enbarrados por matarlos cada dia» (Carrasco y Beroiz, 2009: 198). No es casualidad que un señor acometa dos ataques tan fuertes contra una misma loca-

10 AGN, Comptos, reg, $1{ }^{\mathrm{a} S}, \mathrm{~N} .26,17 \mathrm{v}$. 
Mikel Ursua Lizarbe

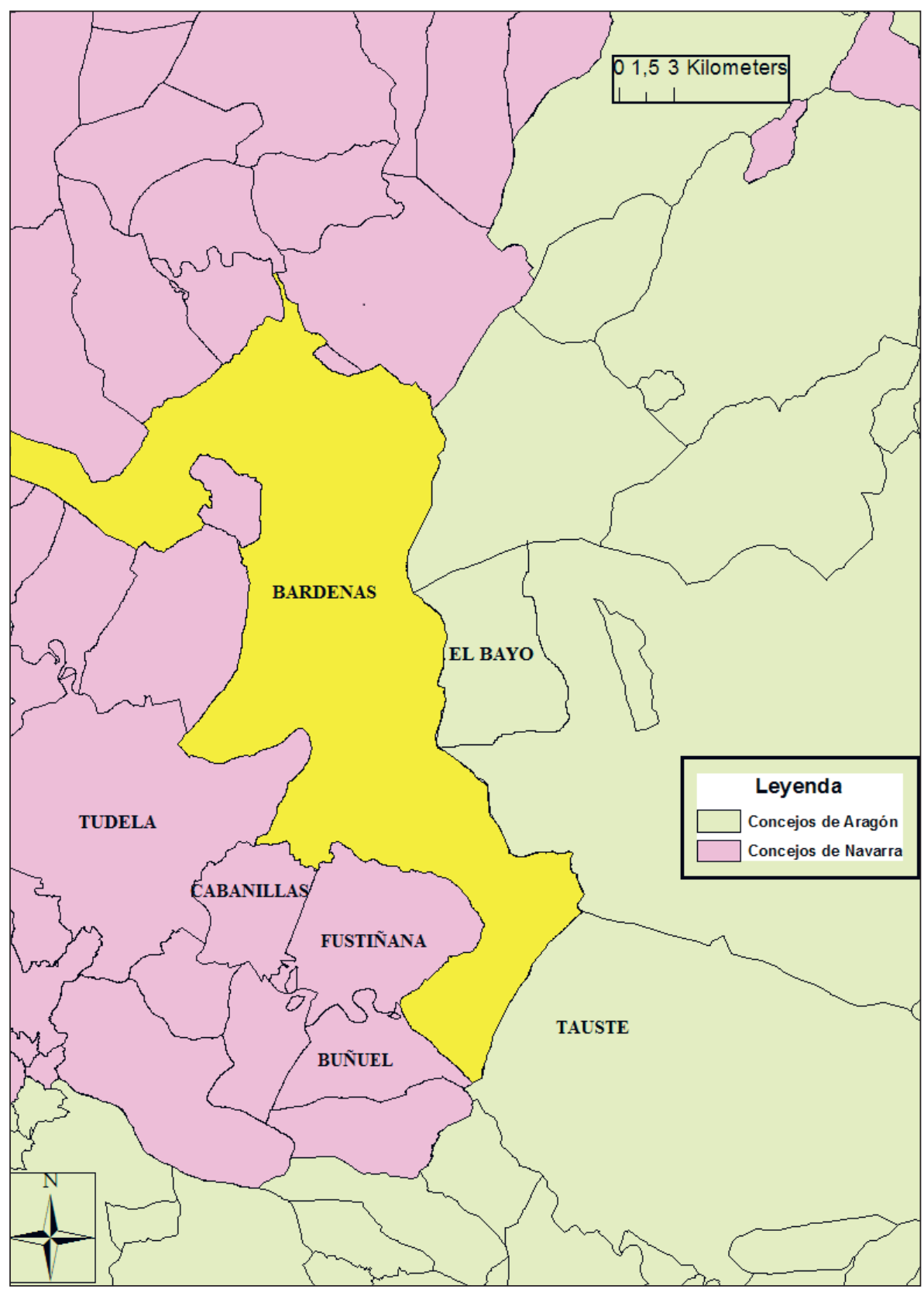

Mapa. 2. Localidades enfrentadas por las Bardenas (1259-1330). 
lidad en un lapso de menos de veinte años. Seguramente existiría alguna motivación para tal acto que desconocemos, quizás la disputa por el espacio. Lo que si podemos afirmar con mayor seguridad es que estas actuaciones no eran simples razzias. En la documentación no se indica que tuviera lugar el robo de propiedades muebles. Solamente se hace mención del ataque contra habitantes del lugar y la ocupación del mismo.

Como hemos podido comprobar, es el dominio y el control del espacio por parte de las comunidades fronterizas la principal causa y motivo de conflicto y enfrentamientos violentos entre las villas y lugares de Navarra y Aragón. ¿De qué forma se manifestaría la posesión de estos espacios por los pretendientes en la disputa? Ocupar y explotar un territorio fue una forma simbólica y efectiva de adueñarse de un territorio, de mostrar al resto quién era el propietario del lugar. Pero la ocupación no fue el único método utilizado en este periodo para reivindicar ante los demás su posesión. La documentación nos ofrece otras formas para cumplir este propósito. Una de ellas fue la destrucción de la propiedad que se reclamaba, como hicieron los sangüesinos en 1317 al darle fuego al Real (Sáinz de la Maza, 1997: 414). Si el espacio irredento pertenecía a sus dominios, todo lo que había en él también le pertenecía, pudiendo arrendarlo y cualquier persona que acudiese a su terreno debía darle una compensación económica. La negativa a pagar por el mismo era resuelta a través de confiscaciones, embargos o prendas. En 1447 gente armada de Sangüesa se apropió del ganado que había en el término de El Real, perteneciente a un ganadero foráneo que había obtenido en arriendo dicho lugar (Juanto y Maruri, 1999: 51). Otra acción podía ser acabar con las reses, como sucedió en la segunda década del siglo XIV cuando los zangozarra enviaron varios hombres para que capturasen y degollasen el ganado que pastaba en El Real (Sáinz de la Maza, 1997: 414-415). En caso de tratarse de una explotación agrícola, podía ser utilizada como tierra de cultivo y el reclamante podía cosecharla, destruirla o en caso de estar yerma, sembrarla. Varios habitantes de Sangüesa entre 1317 y 1320 pusieron en cultivo el término de Ogast y Mongalles (Sáinz de la Maza, 1997: 414-415). En caso de ser una masa forestal el motivo de la discordia, la tala de leña de sus montes podía ser un acto de demanda. Los habitantes del Bayo acudieron a la Bardena para «leuar la dicta fusta» (Carrasco y Tamburri, 2001: 28). Como hemos señalado, en función del aprovechamiento que se daba al terreno, el solicitante del mismo podía actuar de una manera u otra. Pero existía un método menos violento y aparentemente más perdurable que era fijar los límites a través del amojonamiento. En 1497, Antón de Boran, vecino de Sos, a la luz de la noche y acompañado por gente a caballo y a pie, puso los mo- 
jones que existían allá donde quiso en el sector de Sangüesa. Su faena no terminó allí: durante el transcurso de la noche, acudió a los mojones que separaban Sos de Figarol y los derribó (Juanto y Maruri, 1999: 53).

\section{Resolución de conflictos}

Esta alteración del orden público afectó a dos entidades interesadas en resolver la situación: a la monarquía y las comunidades de frontera. La preocupación del rey fue de carácter económico. La inestabilidad afectaba al comercio, fuente de enorme riqueza. En ocasiones eran los mercaderes las víctimas de las marcas, pues según estas, cualquier persona damnificada en el reino vecino podía cobrar su pérdida a través del embargo de bienes sobre cualquier persona del reino en el que sufrió el robo. Por ello, se trató de dar una mayor seguridad a los mercaderes que pasaban de un lado al otro de la frontera, ya que éstos ofrecían ingresos a la corona al tener que pagar un canon en los peajes. Pero no fue el comercio la única motivación. Una localidad afectada por los constantes enfrentamientos podía llevar a la despoblación de la misma, con la merma que ello suponía para las arcas reales. Pero no siempre la situación era tan catastrófica; en ocasiones, la precaria situación económica de las localidades fronterizas en periodos hostiles conllevaba la negociación con la realeza para reducir los impuestos que debían otorgarle.

Por su parte, la comunidad no podía soportar las hostilidades durante tantos años con otros concejos, ni ser la fuente de bienes de los asaltantes. La rutina diaria se veía agitada por ambos fenómenos y repercutía en lo económico. En periodos de enfrentamientos los campesinos podían no atreverse a cosechar un viñedo o un campo de trigo localizado en el espacio de disputa o llevar a apacentar su ganado. Además, en algunos lugares los propios habitantes fueron los encargados de mantener a su costa una pequeña guarnición militar que defendiese los términos. Así podemos ver que en 1427 la localidad roncalesa de Garde, para «guardar los términos et por defenssion de aquillos mantienen por ordenança fecha entre eillos XXIIII vaillesteros a los qoales dan en cada un aynno de penssion por que sean prestos e tengan su mieson a cad'uno X sueldos fuertes que montan XII libras». ${ }^{11}$ 


\subsection{Iniciativa regia}

\subsubsection{Mecanismo ordinario}

La administración real fue la encargada de perseguir y juzgar a los malhechores y defender a las comunidades navarras enfrentadas con las aragonesas. La propia monarquía tenía mecanismos ordinarios para tratar de resolver los conflictos. Estos eran ejercidos por las autoridades a las que el rey delegaba parte de su autoridad. El territorio navarro estaba administrativamente dividido en cuatro circunscripciones hasta 1407 - cinco a partir de dicha fecha-, conocidas como merindades a la cabeza de las cuales se situaba el merino. Esta máxima autoridad poseía por delegación real el supremo poder militar, coercitivo y fiscal (Jimeno, 2013: 321), aunque este deber fue transferido a otros oficiales especializados a lo largo del siglo XIV, los recibidores de merindad (Segura, 2005: 216). El merino no actuaba solo sino con la ayuda y colaboración de subdelegados suyos: el lugarteniente, los sozmerinos en los municipios formados por varias villas y los bailes en los municipios formados por un único núcleo poblacional (Segura, 2005: 215). Entre sus labores estaba la de ejecutar justicia en todo el distrito excepto en algunas circunscripciones menores de cada merindad donde existía otra figura encargada de realizarlo, el almirante en el caso de Sangüesa y el Justicia en Tudela. En el caso de la merindad de Sangüesa, la cabecera no fue la única que formaba una circunscripción administrativa autónoma denominada almiradio. Existieron también en los «valles del Noreste como Salazar, Roncal, Navascués, Aézcoa y en las villas independientes fronterizas de Lumbier, Aoiz, Urroz, Monreal y Larrasoaña» (Juanto, 1996: 313). Además, debía cumplir la función gubernativa de mantener el orden público, siendo el bandolerismo uno de los problemas más preocupantes para la monarquía (Juanto, 1996: 293).

Las autoridades navarras no sólo se implicaron en la búsqueda y castigo del bandolero sino también en la defensa de las localidades afectadas por enfrentamientos. Para ello contrataron un número determinado de soldados, que varió en función de las circunstancias, para proteger las poblaciones navarras del ataque aragonés. Parece ser que estas comitivas tenían un carácter defensivo y no ofensivo, teniendo como deber la protección de los lugares. Ante los ataques del noble Gil de Rada, el merino de Tudela tuvo que contratar en 1312 «10 equitum et 20 peditum» y 6 mesnadas para que protegiese la localidad de Monteagudo (Carrasco y Mugueta, 2004: 117). En 1328, mandó 8 hombres a caballo y 40 
hombres a pie junto a su gente para la defensa del lugar (Carrasco y Beroiz, 2009: 198). Los oficiales actuaban cuando existía un ataque real y también lo hacían cuando llegaban ciertos rumores, como en 1284 cuando llegó a oídos del merino que García Simón junto a la gente de Tarazona querían destruir Monteagudo. Para prevenir un posible ataque, el merino contrató «10 equitum et 40 peditum» que fueron enviados a dicho lugar (Carrasco y Tamburri, 1999: 6).

A pesar de los esfuerzos que los agentes ejecutivos y de justicia desplegaron en Navarra, como acabamos de repasar, el aparato administrativo navarro fue incapaz de terminar con los dos fenómenos que perturbaron la paz en la frontera navarro-aragonesa, el bandolerismo y la violencia entre concejos. Por ello, tanto la monarquía como las poblaciones afectadas tuvieron que recurrir a mecanismos de carácter extraordinario que vamos a tratar de estudiar en este apartado.

\subsubsection{Mecanismos extraordinarios}

Una vez conocidas las acciones emprendidas por la administración ordinaria para lograr la estabilidad y paz fronteriza, pasamos a analizar las actuaciones de carácter extraordinario iniciadas por la autoridad regia y sus delegados. Como acabamos de observar, la administración ordinaria del reino no logró erradicar el mal endémico que se localizaba en las regiones fronterizas, a pesar de las detenciones y castigos ejemplarizantes llevados a cabo por sus oficiales. El miedo infundido no contrarrestaría el incentivo que suponía para los malhechores el conocer la existencia de dos jurisdicciones diferenciadas que imposibilitaba, o por lo menos dificultaba, la actuación de las autoridades al otro lado de la raya.

La conflictividad entre las villas y localidades fronterizas preocuparon enormemente a los reyes de Navarra y Aragón que trataron en época de buenas relaciones mediar en estos enfrentamientos. En 1302, las autoridades conocían sobradamente el motivo por el cual se enfrentaban las comunidades: la indefinición de la línea fronteriza. Para resolver esto decidieron que las villas implicadas, a través de «hommes buenos e fidedignos e ancianos de las villas [...] partamos e moionemos todos los dichos términos en manera que hayan paç e concordia entre sí». De este modo ya no podría haber en el futuro «por aquesta razón [...] entre los dichos regnos discordia alguna» (Zabalza, 1997: doc. 176). El propio Zurita (1985: 251) también alude a la causa del problema: los «mojones de la frontera". 
En 1340 intervinieron en el conflicto que enfrentaron durante toda la Baja Edad Media a Sangüesa y El Real (Zabalza, 1998: 117). En un principio, para resolver la tensión existente, el consejero del rey de Aragón, Lope de Gurrea, acudió a entrevistarse con Renaut, gobernador de Navarra en Olite. En esta reunión, el aragonés expuso las demandas de su rey: «limitassemos o fiziessemos limitar los términos d'entre Nauarra et Aragon, specialment entre las vyllas de Sanguessa et de la Real». Para este propósito concordaron acudir a Cáseda, desde donde empezarían dicha labor. Sin embargo, el enviado navarro tuvo que retornar sin finalizar su tarea porque el comisionado aragonés «non quiso entender en las dichas emiendas». Delimitar una raya no era un proceso sencillo para los comisionados pues cada uno trataba de imponer sus intereses. En 1391 se reunieron Jimeno Cornel, representante del monarca aragonés, y Juan Martínez de Medrano, del navarro, para tratar de acabar con las contiendas fronterizas a través de la partición de los términos. En esta ocasión tampoco consiguieron llegar a un acuerdo porque mientras el aragonés quería empezar la delimitación desde Salvatierra, el navarro quiso hacerlo desde Tauste (Zurita, 1973: 755).

Los agravios cometidos de los unos a los otros nunca finalizaban pues cuando actuaban los de Sangüesa contra El Real, los damnificados no se quedaban de brazos cruzados y poco después pasaban a ser los verdugos, atacando a la localidad vecina. En este enfrentamiento el objetivo era dañar al rival y obtener pequeños botines como pudiera ser ganado, objetos de valor, armamento... Hubo un verdadero ensañamiento con el vecino.

La intervención regía como árbitro para solucionar el conflicto también se pudo apreciar en el conflicto que tuvo lugar durante el siglo XIV entre Buñuel y Tauste. En 1326 ambas localidades y Fustiñana estaban disputándose un espacio de monte localizado más concretamente entre las propiedades regias de Fonyellas y Carxa, el río Ebro y Bardena d'Exeya. ${ }^{12}$ A la espera de la resolución sobre la propiedad del lugar por parte de los reyes, los concejos implicados en el conflicto y varios delegados regios acordaron establecer una serie de medidas para evitar disputas. Por un lado, vedar el acceso al espacio, estableciendo que «non entreen nin usen en nenguna manera la una partida nin la otra». Por lo tanto, cualquier actividad en el espacio de contienda conllevaría su correspondiente sanción: carnereamiento contra el ganado menor y multa contra el mayor; multa económica y pérdida de la pieza al cazador y sanción económica contra aquel que fuera sorprendido talando pinos. 
Otro objetivo del tratado era enmendar los daños realizados entre los vecinos y habitantes de las localidades. Para este fin se creó la figura del veedor. Los navarros nombraron a Johan de Falces como representante de Fustiñana y a Bartolomé de Bruta por Buñuel. Tauste por su parte también nombró dos veedores, Fernando de Oblitas y Beltrán Pérez de Aso. La labor de los oficiales navarros era encargarse «de aquellas cosas que por los d'Thaust contra los de Navarra se demandara tratando de enmendar et pagar aquello que malfeuto sia». Sus compañeros aragoneses harían la misma labor pero a la inversa, ocupándose de las denuncias navarras.

Las partes acordaron una duración de «X annos continuos primeros venientes, saluo empero que si esta composición et coartamiento a los senyores reyes d'Navarra et d'Aragon et a sus logares tenientes no agradiera que lo puedan deproyr et toller dentro del dito tiempo». Efectivamente, la duración del acuerdo quedaba supeditada a la decisión regia, capaz de romper el acuerdo cuando así lo viese necesario, estuviese o no solucionado el conflicto sobre la propiedad del lugar.

Sin embargo, el acuerdo no supuso el retorno a la paz. En 1330 el merino de Tudela tuvo que intervenir en el enfrentamiento que estaba teniendo lugar entre los vecinos de Tauste y Buñuel. Estos segundos se quejaban de que unos taustanos habían segado varias piezas a los navarros. En 1337, los disturbios todavía continuaban, por lo que los reyes de Navarra y de Aragón concordaron crear una comisión que solucionase el problema mediante la colocación de «limitationem aut mugas», nombrando el rey navarro como comisario al gobernador Salhadin de Angelura quien, junto al delegado aragonés, se encargaría de dicha labor (Barragán, 1997: doc. 117).

\subsection{Iniciativa local}

A continuación vamos a analizar aquellas respuestas protagonizadas por las comunidades locales. Según Larrañaga, la violencia entre concejos en razón de los términos, fue el reflejo de un proceso por controlar el espacio. Para evitar disputas, se trató de delimitar territorialmente las aldeas y villas, siendo el amojonamiento el método utilizado para poner fin «a la imprecisa definición de los términos pertenecientes a cada concejo y a los problemas de ella derivados» (Larrañaga, 2005: 119). Parece ser que la delimitación no puso fin a las disputas y tuvieron que recurrir a otro tipos de mecanismos: acuerdos y tratados denominados 'facerías' o 'pacerías'. Para el periodo de nuestro estu- 
dio contamos con dos facerías, las realizadas entre Lumbier y Tiermas en 1366 ${ }^{13}$ y entre Roncal y Ansó en 1407 (Idoate, 1977: doc.10); una concordia entre Isaba y Ansó en $1369^{14}$ y una pacería, encabezada por Peña ${ }^{15}$ y Sos en 1504 (Abella, 2009: doc.188). A través de estos documentos vamos a tratar de establecer tanto las similitudes como las diferencias que existen en estos tipos de acuerdos para obtener los rasgos más característicos de estos tratados.

Ambos vocablos hacen referencia un acuerdo realizado por dos comunidades, como mínimo, en donde se regulan diversos aspectos relacionados con la convivencia, para lograr la paz, término del cual derivaron las voces pacerías y facerías (Tomás y Laliena, 2016: 173). Al estar formado por localidades que pertenecían a distintos soberanos, estos eran considerados tratados internacionales. Estas podían tener dos objetivos (Arizkun, 2004: 300): «regular la explotación común de algunos recursos, especialmente de hierbas y aguas o para institucionalizar la resolución de conflictos». Al primer prototipo pertenecería la concordia celebrada en 1369 entre las villas de Isaba y Ansó, reunidas para «sentenciar, pronunciar, entender, mojonar, poner piedras, señales y cruces» ${ }^{16}$ y acabar con los problemas entre las comunidades. El principal motivo del debate era el disfrute la selva y puerto de Linzola, así como separar precisamente los límites de ambos concejos. Para este fin, los procuradores enviados por las villas amojonaron la frontera a través de piedras, cruces y señales; tras el amojonamiento, acordaron el dominio y uso compartido de Linzola. ${ }^{17}$ Como señalan Tomás t Laliena (2016: 184), con el objetivo de compensar a los roncaleses por la concesión de uso dada a Ansó sobre Linzola, los ansotanos autorizaron que los roncaleses pudieran atravesar su término de Linza para acceder a las zonas más altas del Valle del Roncal.

La pacería y facería formadas en la frontera navarro-aragonesa pertenecieron al segundo prototipo explicado por Arizkun (2004: 300), esto es, al intento de institucionalizar la resolución de los conflictos. Según Larrañaga (2005: 105), fueron el «medio más eficaz para acabar con la conflictividad surgida entre las villas en razón de los términos, especialmente en las fronterizas».

13 AGN. Monasterios, Benedictinas de Lumbier, Leg. 3, n. ${ }^{\circ}$ 23. Copia del siglo XVI. Transcripción aportada por Miguel Larrañaga Zulueta.

14 Archivo Municipal de Ansó, Leg.256/16; Leg.256/11. Copias del siglo XIX.

15 Para este periodo Peña era una villa señorial perteneciente a la familia Ezpeleta.

16 Archivo Municipal de Ansó, Leg.256/16, p.4.

17 Archivo Municipal de Ansó, Leg.256/11, p.4. 
Mikel Ursua Lizarbe

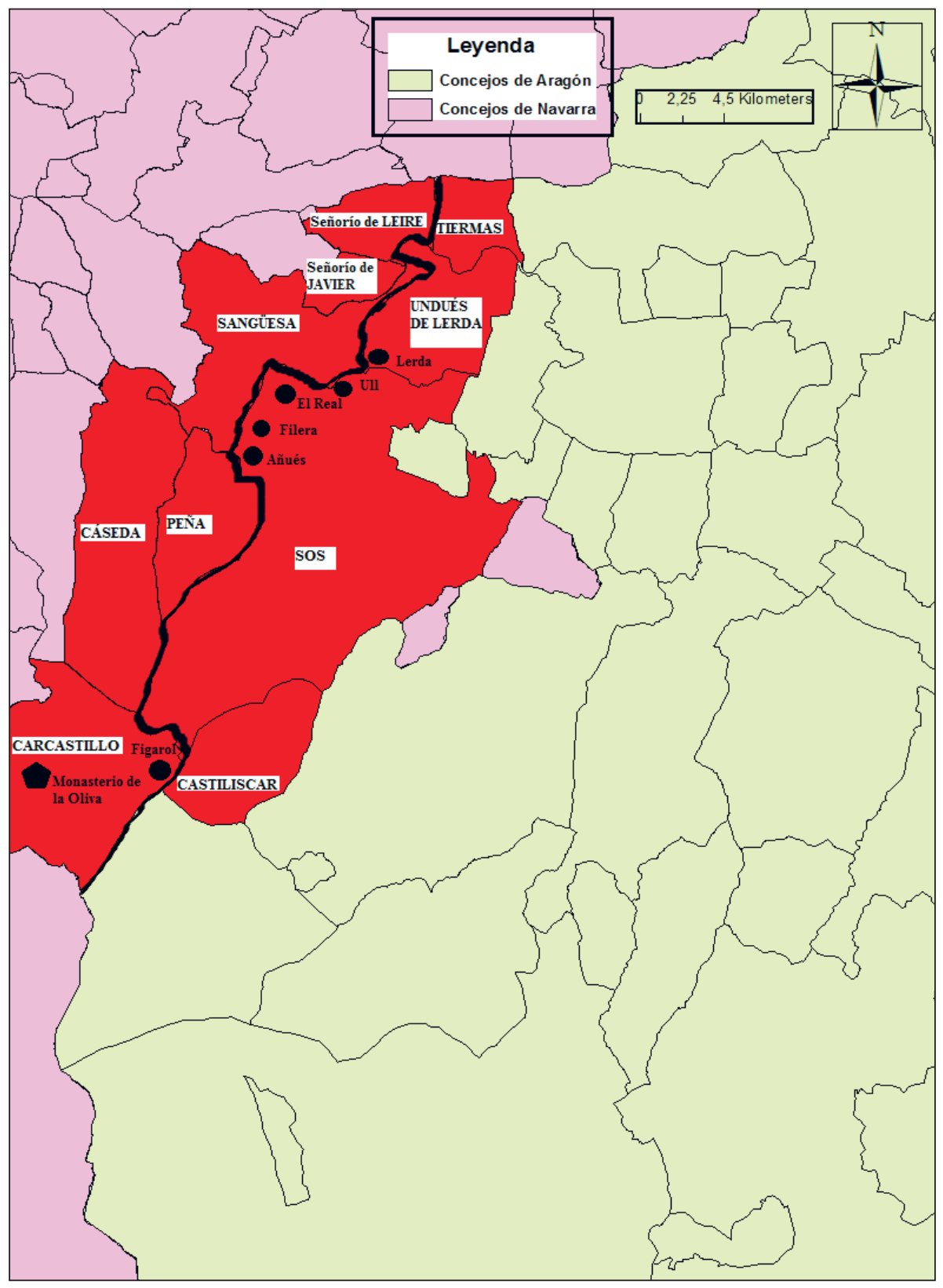

Mapa 3. Facerías y pacerías entre localidades navarras y aragonesas en la Baja Edad Media. 
Para realizar estos acuerdos, los concejos implicados enviaban varios procuradores encargados de establecer y firmar los puntos acordados. Seguramente no sería la primera vez que se reunían pues las condiciones de las facerías o pacerías se habrían negociado anteriormente durante un periodo de tiempo determinado. En la facería de 1366 queda constancia de que acudieron dos procurados por cada villa. En 1407 también asistieron dos representantes por cada concejo implicado para firmar el acuerdo.

Estos procuradores debían presentar en la reunión la carta de procuración otorgada por su concejo, en donde se señalaba que tenían plenos poderes para acordar las condiciones del tratado. Algunas de ellas muestran al principio el motivo por el cual fueron concertadas; en 1366 para «vedrar et esquiar las cosas noçientos, daynossas et procurar et trayr las cosas neçesarrias et provechossas de ambas las dichas universidades». En 1407, para «que sean emendados [...] muertes, plagas, feridas, peçiadurrias, robarías, ladronicios, corrimientos, enbadimientos, fuercas los unos contra los otros [...]». Resolver los conflictos que pudieran derivar de enfrentamientos era la tarea principal, evitando recurrir a la justicia ordinaria, lenta y poco exitosa en la mayoría de los casos. De este modo, los concejos asumían un poder que era competencia del rey, dictaminar justicia, aunque lo delegaba en sus oficiales territoriales. Sin embargo, el propio rey, consciente de que todo ello no era eficaz para acabar con la problemática, no vio con malos ojos delegar en las autoridades concejiles la posibilidad de juzgar ellos los delitos fronterizos. Para que esta nueva legislación no entrase en conflicto con los fueros locales de la población, podían renunciar a ellos, como así hicieron en 1366 Lumbier y Tiermas.

El primer aspecto que regulan estos documentos es el tiempo de vigencia de los mismos. Tanto la facería de 1366 como la pacería de 1504 se establecieron por diez años. En cambio, la de 1407 fue firmada para ciento un años y un día, expresión retórica para señalar la perpetuidad del acuerdo. Una vez finalizada su validez, los implicados podían volver a renovar la facería. En 1504 se introdujo dicha cláusula: «e fenecidos aquellos que duren por tanto tiempo quanto a los dichos concejo de Sos y al dicho senyor d’Ezpeleta, senyor de Penya, plazera».

Las condiciones que se establecieron en estos tratados eran válidas para cualquier habitante de las localidades firmantes. Es decir, todo lo establecido no sólo debía ser cumplido por los vecinos del lugar, sino también por los habitantes. La facería de Roncal y Ansó indicaba esta condición perfectamente: «a ellos et a lures herederos nacidos et a nacer, et a todos los vezinos, gentes et hauitantes de la tierra et uniuerssidat de toda la tierra de val d'Anso». 
En las facerías se podía crear un cuerpo permanente llamado facero o pacero, en función del término empleado. Lumbier y Tiermas crearon este cuerpo formado por seis personas, tres de cada villa.. En la pacería de 1504 también se menciona esta figura, dos personas buenas e idóneas por cada villa. Estas figuras debían cumplir una función, normalmente judicial, aunque no fue la única. Ejercían como jueces, recibiendo la querella y dictaminando sentencia. Pero cada facero sólo podía «sentenciar e determinar las causas e questiones que devant d'ellos cada unos en su districto e sus términos se demandaran». Si el contexto lo requiriese, un delito grave podía ser dirimido por todos ellos. Los cuatro paceros de Peña y Sos podían dar una sentencia de manera conjunta. Todo ello suponía crear una institución supra-local. Otra atribución importante que poseían era poner voz de apellido, es decir, realizar el llamamiento a las poblaciones intervinientes con un objetivo defensivo o de atrapar al malhechor.

Roncal y Ansó establecieron una reunión anual celebrada el tercer día después de Pascua de Pentecostés en la sierra de Puyeta. En ella se congregaban para solucionar los problemas acaecidos entre las dos comunidades, debiendo acudir cuatro procuradores, dos por cada valle. El libro de fuegos de 1427 muestra que estas vistas suponían un enorme gasto para la comunidad, pues no sólo se reunía con la vecina Ansó sino también «con los de Saluatierra de Aragon, de la baill d’Echo, de la baill d'Aspa, de la baill de los baretones, de la tierra de Sola, de la baill de Sarasaz». ${ }^{18}$ Existía una vía de diálogo continua para debatir y alcanzar resoluciones sobre problemas y roces surgidos entre comunidades pirenaicas.

A veces los jueces encargados de dirimir una resolución para poner fin al conflicto, eran incapaces de llegar a un acuerdo, por lo que podían recurrir a la denominada «tercera tierra». Esta normalmente pertenecía a un soberano distinto al que pertenecían los contendientes con el objetivo de que fuese imparcial. Este rasgo es característico de los valles pirenaicos que recurrían al arbitrio de un tercer valle en periodos de disputa. En el tributo de las tres vacas se estableció como árbitro y controlador del cumplimiento de las clausulas firmadas entre Baretous y Roncal al valle de Ansó. En 1407 se dispuso que, en principio, no se llamara a una tercera tierra. Sin embargo, «si los sobredichos quoatro hombres no podiessen concordar, que sia por los primeros tres annyos tercera tierra al villa de Aços, de la tierra de la val d’Aspa; et por otros tres 
annyos siguientes, sea tercera tierra la villa de Eretha, de la val de Barethons; et por conseguient de tres en tres annyos en regla». Es un elemento que diferencia claramente las facerías pirenaicas y las localizadas en lugares más meridionales del reino navarro.

La figura de los faceros o paceros creadas no se superponían a las ya existentes en las localidades participantes. Más bien debían entrelazarse, relacionarse y actuar de manera conjunta y no paralela. En las facerías se establecían las atribuciones de cada uno. En 1504, por ejemplo, se señalaba la importancia que tenían cargos preexistentes como el baile o guarda de un término, quienes eran los encargados de tomar una señal al infractor. En los acuerdos, se trataba de delimitarse los poderes y limitaciones de cada cargo para que no se estorbasen mutuamente y pudiesen colaborar de una manera rápida y eficaz.

Los acuerdos a los que llegaron las localidades sirvieron para regular una normativa procesal y penal que garantizase la concordia (Larrañaga, 2005: 104). Las cláusulas hacen referencia a diversas situaciones derivadas del aprovechamiento forestal, ganadero e incluso agrícola del territorio. Como consecuencia de estos intereses eran factibles roces entre las poblaciones que podían acabar en robos, prendamientos, carnereamiento, heridas, muertes... El objetivo era regular la actuación penal a seguir ante esos acontecimientos y uniformar el castigo que se había de imponer al infractor por haber cometido un determinado delito. Así podemos ver como las multas económicas establecidas por delitos de muerte o heridas. Lumbier y Tiermas acordaron que se pagase quinientos sueldos por muerte y sesenta por herida. Roncal y Ansó, seiscientos por el homicidio y trescientos en caso de herida.

En función de la actividad económica predominante entre los faceros, los intereses variaban. En el caso de los valles pirenaicos la gran mayoría de problemas estaban relacionados con el aprovechamiento ganadero, regulándose la problemática referente al mismo. El ganado era objeto de diversas acciones; podía ser el bien robado, el prendado o el carnereado. En 1407 se reguló la cuantía a pagar por el hurto de ganado: «por cada cabeça, tres cabeças et nueve sueldos de dineros jaqueses por amigadura al querellant». Otro aspecto sancionado legalmente fue el hacer carnal, que regulaba el derecho a carnear el ganado foráneo introducido sin consentimiento en su propiedad. En función del tipo y cantidad de ganado introducido, se establecía el número de cabezas susceptible de ser carnereado. El carnal podía ser sustituido por una caloña o multa, que se veía incrementada por el agravante de nocturnidad. Pero esta 
acción podía ser utilizada de manera ilegal por cualquier individuo en beneficio propio, castigándose con sesenta sueldos cada cabezada de animal carneado ilegalmente.

Las autoridades necesitaban fianzas para asegurarse que el infractor iba a pagar la multa. En 1504 los paceros de Sos y Peña establecieron que el infractor no pudiera excusarse de pagar la multa debiendo dar al baile una señal adecuada. Tras la entrega de la misma, el demandante tenía hasta diez días para pagar la sanción correspondiente y recuperar la fianza. Pasado este plazo, perdía el aval y debía pagar el doble de la multa.

El querellante de una de las localidades faceras podía acudir a las autoridades de la otra para encontrar justicia. Ello podía suponer para el demandante un gasto económico extra, por lo que los faceros debían dar un sostén económico al mismo. En 1366, el demandante debía mantenerse durante los tres primeros días tras poner la querella con sus propios medios, pasado los cuales los faceros de Lumbier debían mantenerlo con doce dineros y sanchetes para sus gastos, hasta la resolución. Pero este apoyo no sólo se traducía en lo económico, también en lo personal. Debían ofrecer protección física al demandante hasta que las autoridades tomasen una resolución sobre la denuncia. Los roncaleses debían «a los dichos de la val d'Anso et singulares della de guardarlos de todo mal e de todo periglo e dayno, e de tornarlos et darlis compaynia o compaynias, en manera que sanos et saluos puedan tornar a sus tierras, todo ello a propias espensas de la dicha val».

Una de las facerías contemplaba la posibilidad de que el acusado pudiese lograr la absolución y evitar de este modo ser multado. Para ello debía presentar leyes, es decir, testigos que tratasen de mostrar su inocencia. En función de la magnitud del delito, el número de testigos a presentar variaba. Por ejemplo, el acusado de asesinato en la facería de 1407 podía librarse con veinticuatro testigos; por robo de ganado, con seis testigos en caso de que lo robado fuese menos de «dos cabeças de ganado mayor et veynte cabeças de ganado menor; et de allí a suso quoanto quiere que sea, que se salue con doze leyes, con si mismo trezeno». Los varones roncaleses tendían a estar lejos de su territorio por motivos de trabajo, por lo que también se regulaba el plazo en el cual debían presentarse a testificar. Si el testigo se encontraba en Bardena u otro oficio que no fuese asalariado, tenían hasta veinte días para declarar; si estaba asalariado o por otro motivo fuera del territorio, tenía tres días para acudir ante el juez, al igual que el individuo que estaba en el territorio. Si no podía acudir en ese espacio de tiempo, siempre tenían la posibilidad de hacer «la ley de 
Pascoa de Penthecosta entroa Todos Santos». La falsa jura recibía no sólo castigo espiritual sino también material.

Otro aspecto primordial era mantener estos reglamentos incluso en periodos bélicos. Los interesados no querían que el enfrentamiento bélico de sus dos soberanos provocase el fin de la estabilidad social en su espacio. Por ejemplo, en 1366 se indicaba que si «oviessen mandamiento cada uno de sus reyes que ficiessen guerra, ante que no fagan ni consientan facer dayno el un conçello al otro». En 1407 se estableció algo similar: «si conteciesse que los señores reyes d'Aragon et de Nauarra ouiessen guerra o debat, que por ayudar los de la val de Roncal a su señor, que en tal caso no se crebante esta paz». Pero no se limitaba a un enfrentamiento directo entre ambas localidades, sino también a la ayuda indirecta, a través de terceros que perjudicasen a la otra localidad facera: «non puedan dar valença ni ayudar a ningún ni ninguna otra persona contra los hombres de la dicha val d'Anso, et singulares de aquella, en personas ni en bienes».

Los faceros no contaban con una fuerza policial permanente que pudiese reprimir a los malhechores, posiblemente por el enorme gasto económico que hubiese supuesto para la hacienda local. En lugar de ello, tenían el deber de acudir en auxilio de una población o tratar de arrestar el malhechor cuando se diese voz de apellido. Era una actuación colectiva que respondía al llamamiento realizado por un oficial, los paceros en el caso de la de 1504. Se castigaba el ser permisivo con los infractores, la omisión de auxilio. La facería de 1367 establecía que en caso de que Lumbier hiciesen llamamiento de apellido y los de Tiermas se abstuviesen de prestar ayuda, deberían «satisfacer et emendar todo el dayno que el dicho (de) Lombier fabra recevido a de falta que non li acorriesen».

En los tratados se establecía una responsabilidad colectiva que exigía hacerse cargo de que el infractor perteneciente a su comunidad pagase la pena correspondiente. ¿Cómo se hacía esto? Si el individuo no poseía dinero para pagar, el concejo podía embargarle sus bienes. Pero en caso de no tener bienes o no ser suficientes, el concejo debía encargarse de pagar la infracción. Roncal y Ansó, determinaron que «si por aventura el mal feytor non ouiesse bienes de que fazer las emiendas a los querellantes [...] el vecinal do el mal factor es, que cumpla la paga al querellant». Sin embargo, dicha comunidad podía eludir hacerse responsable de un malhechor al testificar 12 personas de la localidad que el dicho acusado no pertenecía a la comunidad. 
La creación de este aparato burocrático exigía unos enormes gastos para las comunidades participantes, por lo que recurrieron a métodos tradicionales con los que obtener recursos. Uno de los más conocidos fue cobrar una parte de la multa. Por ejemplo en 1366 la quinta parte de la multa por muerte y la tercera por herida. Sin embargo, esta fuente de ingresos resulta insuficiente, llevándonos a pensar que las poblaciones crearían impuestos directos sobre sus vecinos para sufragar los gastos.

En definitiva, la facería o pacería emanaban de la comunidad local con el objetivo de poner fin a la inestabilidad socioeconómica que causaban los enfrentamientos fronterizos. Observada la ineficacia de la administración regia, las localidades tomaban la iniciativa de negociar este tipo de acuerdos y, a diferencia de la justicia ordinaria, no imponían la pena capital a ningún delito. No tenía esa función ejemplarizante, sino que permitía la reinserción del vecino que había obrado con mala conciencia. Además, cada facería respondía a un contexto espacial y temporal concreto que explicaría las diferencias entre todas ellas, a pesar de compartir ciertos elementos y condiciones comunes.

\section{Conclusiones}

La existencia de una frontera y por tanto, de dos jurisdicciones diferenciadas siempre ha sido un escenario ideal para la existencia de bandolerismo y roces entre las comunidades. El espacio fronterizo entre Navarra y Aragón durante la Baja Edad Media no fue una excepción, siendo la delimitación de la frontera la causa de tantos roces entre comunidades.

El interés por ampliar los límites fronterizos no se debió tanto al interés regio por ampliar el espacio de sus territorios, sino a la iniciativa local por acceder a mejores o mayores recursos naturales como el agua o la madera; o la posibilidad de extender su área de explotación agrícola y ganadera. Esto sucedía en una economía local que recurría a la expansión extensiva para aumentar su producción, conduciendo inevitablemente al choque entre las comunidades por controlar o apropiarse de mayores espacios.

Los enfrentamientos entre las comunidades pudieron ser puntuales o constantes a lo largo del tiempo, como así sucedió entre Sangüesa y Sos. La inestabilidad en los espacios de frontera suponía un problema para las comunidades y para la propia corona. La administración del reino podía perder ingresos económicos al reducirse los intercambios comerciales así como consecuencia 
de la despoblación de los lugares. También podía suponer la caída de su sistema defensivo, ya que las comunidades en ocasiones eran las encargadas de mantener o reparar las fortalezas locales.

Por estos motivos, y visto que los mecanismos ordinarios de la administración no lograban detener la espiral de violencia, la monarquía decidió emprender medidas de carácter extraordinario: la creación de comisiones entre delegados navarros y aragoneses para amojonar y delimitar la frontera o la intervención y posterior creación de tratados de paz entre los concejos enfrentados. Sin embargo, parece ser que la administración central no logró acabar con los enfrentamientos.

La violencia fronteriza perjudicó en mayor medida a las propias comunidades, viéndose la rutina diaria y la actividad económica agitada por la inestabilidad, además de suponer un enorme gasto para la misma al tener que mantener guarniciones militares a su cargo. Por ello, la comunidad fue la más interesada en resolver las relaciones hostiles en la frontera a través de un mecanismo muy conocido utilizado entre los valles pirenaicos: la facería o pacería. Nacidos de la iniciativa local, estos tratados intercomunitarios trataron de regular la convivencia en la frontera, asumiendo una competencia regia, poder ejercer la justicia en su jurisdicción, con la finalidad de poder alcanzar la tan ansiada paz.

Al parecer los acuerdos nacidos por iniciativa local fueron más exitosos que las de origen regio, en el sentido de que fueron capaces de resolver ellos mismos los episodios de violencias, sin intervención regia. Esta hipótesis queda avalada a través de dos documentos conservados en el Archivo General de Navarra.

El primero de ellos es el diario de la comisión de frontera navarro-aragonesa de $1380,{ }^{19}$ la cual recoge denuncias de los agraviados por habitantes del reino vecino desde 1360. Este periodo coincide con el periodo en el que estuvo vigente la comisión entre Lumbier y Tiermas de 1366. En el diario, no se recoge ni una denuncia entre vecinos de dichas villas, lo cual demuestra que las querellas de ambas comunidades seguían el cauce establecido por la facería en 1366.

El segundo de ellos es un documento realizado por el abad de Garde quien recogió por escrito las querellas de los Roncaleses y Salacencos sobre agra- 
vios cometidos por aragoneses contra ellos entre los años $1411-1416,{ }^{20}$ contemporáneo a la facería acordada por los valles de Roncal y Ansó en 1407. De nuevo, no se recoge ninguna querella contra algún vecino ansotano, confirmando que las facerías fueron capaces de manera autogestionada por las propias comunidades firmantes crear una estructura y funcionamiento judicial capaz de resolver por sí sola cualquier problema surgido entre las mismas.

\section{Referencias bibliográficas}

Abella SAmitier, Juan (2009), Selección de documentos de la villa aragonesa de Sos (1202-1533). Zaragoza, Institución Fernando el Católico.

ABELLA SAMITIER, Juan (2011), «La comarca de la Valdonsella en las relaciones entre Aragón y Navarra a finales de la Edad Media», Príncipe de Viana, 253: 335-347.

ACHÓN INSAUSTI, José Ángel (1988), «Los intereses banderizos en la definitiva configuración de la frontera entre Guipúzcoa y el reino de Navarra», Príncipe de Viana. Anejo, 8: 257-266.

APARICIO RosiLlo, Susana (2007), «La violencia en Gascuña y los enfrentamientos anglo-navarros (siglos XIII y XIV)», Huarte de San Juan. Geografía e Historia, 14: 9-31.

APARICIO Rosillo, Susana (2011), «'Por las malefacturas que se fazian entre las tierras de Çapuertos e la tierra de Labort.' La compleja definición de la frontera medieval y su control según el ejemplo navarro de Ultrapuertos (siglos XIII y XIV)», Miscalánea medieval murciana, 35: 9-26.

ARIZKun CELA, Alejandro (2004), «Las facerías en el Pirineo Navarro: una perspectiva histórico-económica», Iura vasconiae: revista de derecho histórico y autonómico de Vasconia, 1: 299-314.

AZCÁRATE AGUILAR-ARNAT, Pilar (1986), «Hostilidades en la frontera navarro-riojana durante el siglo XIV: el choque de los años 1344-1345», en Segundo Coloquio sobre Historia de La Rioja. Logroño, Colegio Universitario de la Rioja. Vol. 1: 333-344.

AZCÁRATE AgUILAR-ARNAT, Pilar (1988), «Un nuevo episodio de la rivalidad entre villas navarras y riojanas: los disturbios de 1355», Anuario de estudios medievales, 18: 329-336.

BARRAgÁn Domeño, María Dolores (1997), Archivo General de Navarra (13221349). Documentación real. Vol. I. San Sebastián, Eusko Ikaskuntza.

CAMPIÓN, Arturo (1911), «La frontera de los malhechores: el bandolerismo de 1261 a 1332, la 'facienda' de Beotíbar, la toma de Hernani», Boletín de la Comisión de Monumentos Históricos y Artísticos de Navarra, t. II: 67-75.

20 AGN, Comptos_PS, $1^{\mathrm{a}} \mathrm{S}$, Leg. $167, \mathrm{~N}^{\mathrm{o}} 31$. 
CAMPIÓn, Arturo (1915), «Gacetilla de la Historia de Nabarra, Crónica negra», Euskariana, Pamplona, $5^{\text {a }}$ ser. , vol. III, 241-423.

CAMPIÓn, Arturo (1983), Obras completas. Mosaico histórico (II). Pamplona, Mintzoa.

CARRASCO, Juan y Pascual TAMBURRI (1999), Registros de la casa de Francia: Felipe I el Hermoso (1284, 1285, 1286, 1287). Serie I: Comptos Reales. Registros. T. II, vol. II. Pamplona, Gobierno de Navarra.

CARrasco, Juan, Pascual TAmburri e Íñigo Mugueta (2001), Registros de la casa de Francia: Felipe I el Hermoso (1297-1298, 1300, 1304). Serie I: Comptos Reales. Registros. T. V. Pamplona, Gobierno de Navarra.

CARrasco, Juan e Íñigo Mugueta (2004), Registros de la casa de Francia: Luis el Hutín (1311-1314). Serie I: Comptos Reales. Registros. T. IX. Pamplona, Gobierno de Navarra.

Carrasco, Juan, Marcelino Beroiz e Íñigo Mugueta (2005), Registros de la Casa de Francia: Luis I el Hutín / Felipe II el Largo (1315-1318). Serie I: Comptos Reales. Registros. T. X. Pamplona, Gobierno de Navarra.

CARrasco, Juan y Marcelino BeroIZ, (2009), Registros de la Casa de Francia: Carlos I el Calvo (1328). Serie I: Comptos Reales. Registros. T. XII, vol. 1. Pamplona, Gobierno de Navarra.

CARrasco, Juan, Mikel GoÑI e Íñigo Mugueta (2010), Registros de la casa de Francia: Carlos I el Calvo (1328). Serie I: Comtpos Reales. Registros. T. XII. Vol. 2, Pamplona, Gobierno de Navarra.

CASTEllano GutiéRREZ, Antonio (1995), «La Hermandad navarro-aragonesa en la frontera pirenaica según sus ordenanzas. Segunda mitad del siglo XV», Príncipe de Viana, 204: 121-162.

Diago HeRnANDo, Máximo (2013), «Los efectos de las guerras entre los Trastámara de Castilla y Aragón sobre las comarcas de frontera durante el siglo XV», en María Isabel Falcón Pérez, coord., El compromiso de Caspe (1412), cambios dinásticos y Constitucionalismo en la Corona de Aragón. Zaragoza, Gobierno de Aragón: 304-313.

ESTEBAn, Juan P. (1921), «El castillo de Sancho Abarca», Boletín de la Comisión de Monumentos Históricos y Artísticos de Navarra, XII/47: 177-180.

FERnÁndeZ DE LARREA, Jon Andoni y José Ramón DíAZ DE DURANA (2002), «Economía ganadera y medio ambiente. Guipúzcoa y el Noreste de Navarra en la Baja Edad Media» Historia agraria: Revista de agricultura e historia rural, 27: 43-64.

FERnÁNDEZ MARCO, Juan Ignacio (1978), Cascante, ciudad de la Ribera. Vol. 1. Pamplona, Institución Príncipe de Viana.

FORTÚN PÉREZ DE CIRIZA, Luis Javier (1993), Leire, un señorío monástico en Navarra (siglos IX-XIX). Pamplona, Gobierno de Navarra.

GARCÍA ARANCÓN, María Raquel (1989), «Relaciones navarro-aragonesas a mediados del siglo XIII» Mayurqa: revista del Departament de Ciències Històriques i Teoria de les Arts, 22: 269-280. 
GLICK, Thomas F. (1991), Cristianos y musulmanes en la España medieval (7111250), Madrid: Alianza.

HerRero LiCEAGA, Victoriano J. y José Luis Orella UnZuÉ (1988), «Las relaciones comerciantes entre Navarra y Guipuzcoa desde mediados del siglo XIV hasta mediados del siglo XV», Príncipe de Viana. Anejo, 8, 491-500.

IdoATe IRAgui, Florencio (1977), La comunidad del Valle del Roncal. Pamplona, Diputación Foral de Navarra.

Jimeno JuRío, José María (2013), Navarra. Síntesis histórica y geográfica. Pamplona, Pamiela.

JuAnto JimÉnEZ, Consuelo (1996), La Merindad de Sangüesa. Estudio histórico y jurídico. Pamplona, Gobierno de Navarra.

JuANTO JimÉnEZ, Consuelo y David MARURI ORRANTIA (1999), «La villa del RealSangüesa», Zangotzarra, III/3: 11-107.

Larrañaga Zulueta, Miguel (2005), Campesinado y conflictividad social en la Navarra bajomedieval. Segovia, Universidad SEK.

Monteano Sorbet, Peio I. (1996), «Navarra de 1366 a 1428: población y poblamiento», Príncipe de Viana, 208: 307-344.

Moret, José de y Francisco de Alesón (1969), Annales del reyno de Navarra. Vol. 3. Bilbao, Gran Enciclopedia Vasca.

MugueTA, Íñigo (2000), «Acciones bélicas en Navarra: La frontera de los malhechores (1321-1335)», Príncipe de Viana, 219: 49-78.

Munita Loenaz, José Antonio (1995), El monasterio de la Oliva en la Edad Media (siglos XII al XVI). Historia de un dominio cisterciense navarro. Vitoria-Gasteiz, Universidad del País Vasco / Euskal Herriko Unibertsitatea.

ORELla UnZuÉ, José Luis (1984), «Los orígenes de la Hermandad de Guipúzcoa: las relaciones Guipúzcoa-Navarra en el siglo XIII-XIV», Vasconia: Cuadernos de historia-geografía, 3: 25-100.

ORElla UnZUÉ, José Luis (1985) «La Hermandad de Frontera entre Navarra y Guipúzcoa, s.XIV y XV», Príncipe de Viana, 175, 463-492.

Orella Unzué, José Luis, José Ángel Achón InSAUSTI y Peru SÁIz ElizOndo (1987), Guipúzcoa y el Reino de Navarra en los siglos XIII-XV: relaciones, intereses y delimitación de frontera, San Sebastián, Universidad de Deusto.

Orella Unzué, José Luis y José Ángel AcHón InSAUSTI (1988), «Los intereses de la villa de Tolosa en la frontera navarro-guipuzcoana», Príncipe de Viana. Anejo, 8: 267-276.

PALACIOS MARTín, Bonifacio (1979), «La frontera de Aragón con Castilla en la época de Jaime I», en Jaime I y su época. Zaragoza, Institución Fernando el Católico. Vol. 2: 475-495.

ROMANO, David (1977), «Ulle de Sangüesa + Filera = La Real: antiguas poblaciones cerca de Sos, 1301», Principe de Viana, 148-149: 435-438.

SÁINZ DE LA MAZA LASOLI, Regina (1997), «Hostilidades en la frontera navarroaragonesa durante el reinado de Jaime II», en XV Congreso de Historia de la Co- 
rona de Aragón. Actas. II. Relaciones de la Corona de Aragón con los estados cristianos peninsulares (siglos XIII-XV), Zaragoza, Diputación General de Aragón: 409-423.

SÁiz ElizOndo, Peru y José Ángel ACHón InSAusti (1988), «Los amojonamientos de los términos municipales de Rentaría, Oyarzun y Fuenterrabía en la segunda mitad del siglo XI: la conclusión de un proceso de delimitación espacial en la frontera entre Guipúzcoa y el Reino de Navarra», Príncipe de Viana. Anejo, 8: 277 286.

SEgURA URRA, Félix (2005), Fazer justicia. Fuero, poder público y delito en Navarra (siglos XIII-XIV). Pamplona, Gobierno de Navarra.

SEgura URRA, Félix (2013), «Fuentes documentales para la historia del crimen y el castigo en el Archivo Real y General de Navarra»Clío \& Crímen: Revista del Centro de Historia del Crimen de Durango, 10: 115-153.

Sociedades de frontera, Las. Sesiones de trabajo. II Seminario de Historia Medieval. Anejo de Aragón en la Edad Media. Zaragoza, Universidad de Zaragoza, 1993.

Tomás FaCI, Guillermo y Carlos LALIENA CORBERA (2016), Ansó. Historia de un valle pirenaico, Huesca, Editorial Pirineo.

ZÁBALO ZABALEGUI, F. Javier (2004), «Una encuesta de 1349 sobre bandoleros navarros y guipuzcoanos», Príncipe de Viana, 232: 477-510.

ZÁBALO ZABALEGUI, F. Javier (2005), «El acoso de guipuzcoanos y alaveses a los ganaderos navarros. La frontera de los malhechores entre 1280 y 1349», Príncipe de Viana, 234: 53-110.

ZaBAlZA AldAVE, María Itziar (1997), Archivo General de Navarra (1274-1321). II. San Sebastián, Eusko Ikaskuntza.

ZabalZa AldAVE, María Itziar (1998), Archivo General de Navarra (1322-1349). II. San Sebastián, Eusko Ikaskuntza.

ZuRITA, Jerónimo [1973], Anales de la Corona de Aragón. Vol. 4. Zaragoza, Institución Fernando el Católico.

ZURITA, Jerónimo [1985], Índices de las gestas de los reyes de Aragón desde comienzos del reinado al año 1410. Vol. 1. Zaragoza, Institución Fernando el Católico. 
